\title{
Water Defluoridation Capacity of Tanzanian Kaolin-Feldspar Blend Adsobents
}

\author{
Esther Hellen Lugwisha ${ }^{1, ~ *, ~ G a l a s i a ~ L u n y u n g u ~}{ }^{2}$ \\ ${ }^{1}$ Chemistry Department, University of Dar es Salaam, Dar es Salaam, Tanzania \\ ${ }^{2}$ Chang'ombe Secondary School, Dar es Salaam University College of Education, Dar es Salaam, Tanzania
}

Email address:

elugwisha@gmail.com (E. H. Lugwisha), galasia.lunyungu@gmail.com (G. Lunyungu)

${ }^{*}$ Corresponding author

\section{To cite this article:}

Esther Hellen Lugwisha, Galasia Lunyungu. Water Defluoridation Capacity of Tanzanian Kaolin-Feldspar Blend Adsobents. American Journal of Applied Chemistry. Vol. 4, No. 3, 2016, pp. 77-83. doi: 10.11648/j.ajac.20160403.12

Received: March 29, 2016; Accepted: April 8, 2016; Published: April 27, 2016

\begin{abstract}
A study was conducted to investigate the capacity of Tanzanian kaolin-feldspar blends on water defluoridation. Five adsorbents of kaolin-feldspar blends were prepared at different ratios, namely; 1:0, 1:1, 1:2, 2:1 and 0:1. The prepared adsorbents were activated at $60^{\circ} \mathrm{C}$ and then characterized by XRD and XRF. Mineralogical results showed that kaolin contained phases of kaolinite, illite and quartz whereas feldspar contained microcline and quartz. Chemical composition results indicated that both kaolin and feldspar samples contained silica and aluminium in high proportions. Defluoridation studies were conducted by using column method. Different parameters were tested for water defluoridation studies including particle size, contact time, initial fluoride ion concentration, height of the column and solution $\mathrm{pH}$. It was observed that the adsorption increased with a decrease in particle size, and particle size of $0.25 \mathrm{~mm}$ showed the highest removal of fluoride. The fluoride adsorption was found to increase with contact time with optimum contact time after 45 minutes. A high adsorption of fluoride ions for all samples was observed at low pHs (2-6) and the maximum adsorption was at $\mathrm{pH} 2$. Also the adsorption increased as the height of the column was increased. Regeneration of spent adsorbent did not afford to remove fluoride to acceptable levels, an aspect that needs more investigation. The study therefore concludes that, although the blends can be used as defluoridation materials; blending kaolin and feldspar did not improve adsorption of fluoride ions from fluoridated water. The best adsorbent was B1 which consists of kaolin only followed by B2 with 2:1 kaolin-feldspar ratio.
\end{abstract}

Keywords: Water Defluoridation, Kaolin, Feldspar, Blends, Tanzania

\section{Introduction}

Fluoride in drinking water could be beneficial or detrimental for health depending on its concentration and total amount ingested. The presence of fluoride in drinking water is beneficial for calcification of dental enamel, in particular for children under eight years old. Potable water can be fluoridated to prevent tooth decay if the level of fluoride is less than $1.0 \mathrm{mg} / \mathrm{L}[1,2]$. However, excess fluoride intake (more than $1.5 \mathrm{mg} / \mathrm{L}$ ) causes dental and skeletal fluorosis [1, 3]. As reported in literature [3, 4], many regions in Tanzania have been identified to have high levels of fluoride concentration in groundwater above the permissible limit of $1.5 \mathrm{mg} / \mathrm{L}[1,3]$. The regions are in the rift valley zones in northern and south-western Tanzania which are associated with volcanic activity. These regions include Shinyanga, Tabora, Dodoma, Singida, Arusha, Kilimanjaro, Mara, Manyara, Mbeya and Rukwa [3].

Several techniques which aim at reducing the level of fluoride in drinking water to permissible limits have been reported in the literature $[5,6]$. The techniques are mostly categorized in four major types, namely: adsorption, ion exchange, precipitation and membrane processes which include reverse osmosis and electrochemical methods. Among the techniques reported, adsorption technique seems to be the most effective and convenient because of its ease of operation and effectiveness. However, the capacity of the adsorption technique depends on the nature of adsorbents. Different sorbent materials used for adsorption include activated alumina, clay, activated carbon, zeolite, calcite and fly ash. On 
the other hand, ion exchange method makes use of synthetic resins which possess high exchange capacity. Fluoride in water exchanges for chloride due to its high electronegativity. Bone char as well removes fluoride based on the ion exchange principle. Defluoridation by precipitation method is based on soluble salts such as $\mathrm{CaCl}_{2}, \mathrm{CaSO}_{4}$ and $\mathrm{Ca}(\mathrm{OH})_{2}$ which are added in water and an insoluble salt of fluoride is formed. Membrane processes involve application of electric current and reverse osmosis in removing fluoride from water. Membrane processes are very costly in installation and maintenance, thus are not popular in developing countries like Tanzania.

The aforementioned defluoridation methods are either expensive, have low rate of fluoride removal, subject to ethical rejection or need expertise above villagers' level [7, 8]. The use of kaolin blended with feldspar in water defluoridation is one of the methods envisaged to circumvent these shortcomings because both kaolin and feldspar are found and are cheaply obtainable in many places in Tanzania. In addition, kaolin consists of aluminium which is capable of adsorbing fluoride and consists of hydroxide ions capable of exchanging with fluoride ions. Feldspar, on the other hand, consists of aluminium and other metals such as $\mathrm{Na}, \mathrm{Ca}$, and $\mathrm{K}$ which can also provide binding sites for fluoride. Thus, this work aimed at studying the capacity of kaolin - feldspar blend for water defluoridation.

\section{Material and Methods}

\subsection{Collection of Samples}

Kaolin was collected from Pugu forest reserve which is located twenty five kilometres south-west of Dar es Salaam. Feldspar was obtained from Southern and Eastern African Mineral Centre (SEAMIC). The samples were stored in plastic bags and transported to Chemistry Department Laboratory, University of Dar es Salaam for activation and defluoridation studies.

Table 1. Ratio Sample of Kaolin and Feldspar.

\begin{tabular}{llll}
\hline B1 & B2 & B3 & B4 \\
\hline K: F & K:F & K: F & K:F \\
$1: 0$ & $2: 1$ & $1: 1$ & $1: 2$ \\
$300 \mathrm{~g}: 0 \mathrm{~g}$ & $200 \mathrm{~g}: 100 \mathrm{~g}$ & $150 \mathrm{~g}: 150 \mathrm{~g}$ & $100 \mathrm{~g}: 200 \mathrm{~g}$ \\
\hline
\end{tabular}

K: Kaolin; F: Feldspar

\subsection{Characterization of Samples}

Prior to the analysis for X-Ray Diffraction (XRD) and $\mathrm{X}$-Ray Fluorescence (XRF), kaolin and feldspar powder were dried in a vacuum oven at $100^{\circ} \mathrm{C}$ for six hours to remove moisture content and then cooled to room temperature.

X-Ray Diffraction (XRD) patterns of both kaolin and feldspar were obtained using InXiTU Material diffractometer (model BTX 231) connected to a Lap top computer (model HP 530) which was installed with InXiTU BTX Interface software. $20 \mathrm{mg}$ of the sample was homogenized into a fine powder by magnetic shaker before it was inserted into the XRD for analysis.

$\mathrm{X}$-Ray Fluorescence (XRF) investigations were carried out using Bruker XRF Spectrometer (Model S8 Tiger). Pellets of $34 \mathrm{~mm}$ diameter were prepared from the sample powder. Few drops of boric acid were added to the pellets for the purpose of holding and labeling. The pellets were placed in the sample chamber of the XRF for analysis.

\subsection{Preparations of Samples and Reagents for Water Defluoridation}

\subsubsection{Preparations of Samples}

Kaolin was dried in a an oven at $100^{\circ} \mathrm{C}$ for 2 hours and then ground to fine powder by using mortar and pestle. Then each of kaolin and feldspar powder was made into small blocks. The blocks were fired in a high temperature muffle furnace F46120CM at a temperature of $600^{\circ} \mathrm{C}$ for six hours. The fired blocks were then left to cool for one day/24 hours before they were ground to obtain particle size from the sieves with mesh dimensions of 2.00, 1.40, 0.30 and $0.25 \mathrm{~mm}$. Five samples namely B1-B5 of various ratios as shown in Table1 were prepared as per these particle sizes (from kaolin and feldspar) and were used as adsorbents for water defluoridation.

\subsubsection{Preparations of Reagents}

Total Ionic Strength Adjustment Buffer (TISAB II) was prepared as follows: $57 \mathrm{~mL}$ of glacial acetic acid, $58 \mathrm{~g}$ of sodium chloride $(\mathrm{NaCl}), 2 \mathrm{~g}$ of ethyelenediaminetetraacetic acid (EDTA) and $7 \mathrm{~g}$ of sodium citrate were added to $500 \mathrm{~mL}$ of distilled water. The $\mathrm{pH}$ was adjusted to between 5 and 5.5 by adding $5 \mathrm{M} \mathrm{NaOH}$ solution drop wise, and then the solution was made to $1 \mathrm{~L}$ with distilled water.

Sodium hydroxide $(\mathrm{NaOH})$ solution $(5 \mathrm{M}$ and $0.1 \mathrm{M}$ ) were prepared by dissolving $20 \mathrm{~g}$ and $0.4 \mathrm{~g}$ of $\mathrm{NaOH}$ pellets, respectively, in separate beakers each containing $200 \mathrm{~mL}$ of distilled water then transferred to a $1 \mathrm{~L}$ volumetric flask and diluted to the mark. Also, $0.1 \mathrm{M} \mathrm{HCl}$ was prepared by diluting $8.73 \mathrm{~mL}$ of $11.46 \mathrm{M}$ of concentrated $\mathrm{HCl}$ with distilled water to make $1 \mathrm{~L}$ solution.

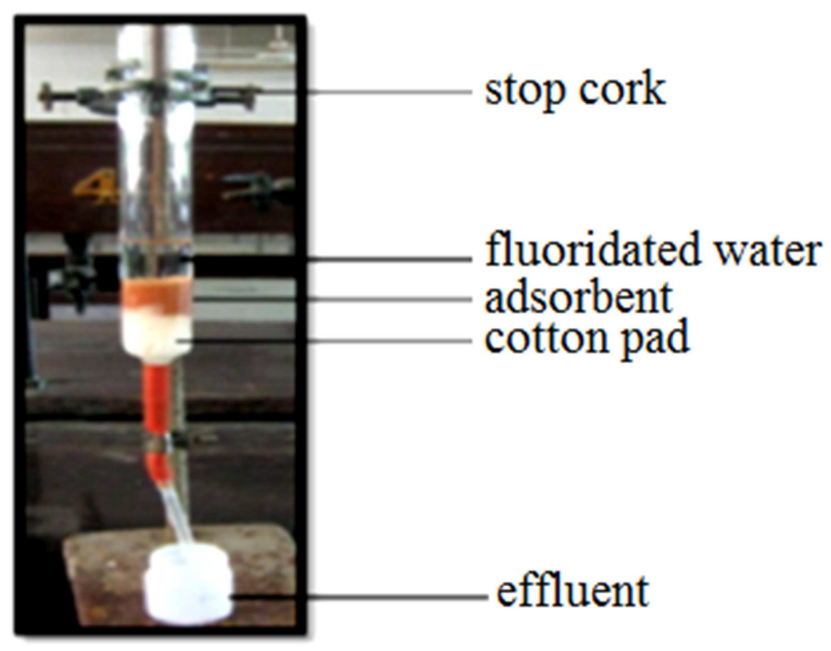

Figure 1. A Defluoridation Column. 


\subsection{Column Packing}

Glass type columns with diameters of $2.5 \mathrm{~cm}$ were used. The columns were washed with water and rinsed with distilled water. A cotton pad was placed between the adsorbent and the stop cork before packing the column so as to prevent the sample from escaping through (Figure 1). In addition, a cotton pad facilitated the filtration of the defluoridated water.

\subsection{Fluoride Ion Concentration Analysis in Water}

The analysis of fluoride in water was carried out in the Chemistry laboratory at the University of Dar es Salaam by a potentiometric method using ion selective electrode (ISE) meter. The fluoridated water was mixed with TISAB II in the ratio of $1: 1(10: 10) \mathrm{mL}$ and transferred into a $50 \mathrm{~mL}$ sterile plastic container and shaken well to ensure the contents were homogeneously mixed. The ISE meter was calibrated before using it. The concentrations used for calibration were 2, 5 and $10 \mathrm{mg} / \mathrm{L}$. Quality control was done by using $5 \mathrm{mg} / \mathrm{L}$ of which five replicates were measured. The measurement was done by immersing the electrodes in the beaker and the concentration of fluoride ions was recorded after four minutes so as to get a constant value.

\subsection{Fluoride ion Adsorption Studies Using Kaolin-Feldspar Blend Adsorbents}

Fluoride ion adsorption studies were conducted by varying the following parameters: adsorbent particle size, contact time, initial fluoride concentration, height of the bed column, and $\mathrm{pH}$.

\subsubsection{The Effect of Particle Size on Deflouridation Capacity of Kaolin-Feldspar Adsorbents}

The effect of particle size was carried out using adsorbents with particle sizes of $2.00,1.40,0.30$ and $0.25 \mathrm{~mm}$. The columns were packed with $20 \mathrm{~g}$ of the adsorbent samples and $50 \mathrm{~mL}$ of $5.03 \mathrm{mg} / \mathrm{L}$ fluoridated water was allowed to come in contact with the adsorbents for 45 minutes. The effluents were collected and analyzed using fluoride ion selective electrode method to establish the percentage removal of fluoride ions and the results were recorded.

\subsubsection{The Effect of Contact Time}

In order to determine the minimum contact time which gives out the maximum removal of fluoride, five columns packed with the adsorbents (B1-B5) at different experiment set up were set and $50 \mathrm{~mL}$ of $5.03 \mathrm{mg} / \mathrm{L}$ of fluoridated water was passed through the columns. The effluents were collected at 15, 30, 45, 60 and 75 minutes intervals for each adsorbent. The experiments were done in triplicates. Measurement of fluoride was done to the collected effluents, the results were recorded and a plot of recovered fluoride concentration versus time of contact was drawn and the minimum effective contact time determined.

\subsubsection{The Effect of Initial Fluoride Concentration}

The effect of initial fluoride concentration was determined using the selected concentrations: 5, 10, 15, 20 and $25 \mathrm{mg} / \mathrm{L}$. A 20 g-sample of the adsorbent was packed in a column and fluoridated water samples were left in contact with the column for 45 minutes. The experiments were done in triplicates for each concentration. Analysis of fluoride was carried out and the results recorded.

\subsubsection{The Effect of the Height of the Column}

The effect of the height of the column was determined by varying the height of the column. The selected heights were $0.8,1.6,2.4,3.2,4.0,4.8,5.6,6.4$, and $7.2 \mathrm{~cm}$. The fluoridated water with concentration of $5.03 \mathrm{mg} / \mathrm{L}$ was passed through each column packed with $20 \mathrm{~g}$ of $1.40 \mathrm{~mm}$ average particle size adsorbents for 45 minutes. The effluents were collected in plastic containers, analysed for fluoride and the results were recorded.

\subsubsection{The Effect of the $\mathrm{pH}$}

The effect of $\mathrm{pH}$ of fluoridated water was determined. The selected pHs were $2,4,6,8,10,12$, and 14 . The adjustment of the $\mathrm{pH}$ was done by using $0.1 \mathrm{M} \mathrm{NaOH}$ and $0.1 \mathrm{M} \mathrm{HCl}$ solutions. The fluoridated water with initial fluoride concentration of $5.03 \mathrm{mg} / \mathrm{L}$ was allowed to be in contact with adsorbent blends for 45 minutes. The effluents were collected, analysed for fluoride and the results recorded.

\subsection{The Regeneration of the Fluoride Saturated Adsorbent}

Regeneration of the exhausted adsorbent (B1 was chosen) was done by adding $100 \mathrm{ml}$ of $1 \% \mathrm{NaOH}$, shaken left to stand, followed by decantation. Washing of the adsorbents using 100 $\mathrm{ml} 1 \% \mathrm{NaOH}$ solution was done twice. Thereafter, the adsorbent was washed with $100 \mathrm{~mL}$ of distilled water (8 times) and dried in an oven at $100^{\circ} \mathrm{C}$ for 2 hours. The regenerated B1 was then tested as follows: $20 \mathrm{~g}$ of the regenerated $\mathrm{B} 1$ having the average particle size of $1.4 \mathrm{~mm}$ was packed in a column. Fluoridated water with initial fluoride concentration of 5.03 $\mathrm{mg} / \mathrm{L}$ was passed through column. Collection of the effluent was done continuously at the flow rate of $1 \mathrm{~mL}$ per minute. Eight (8) effluents of B1 were collected and analysed for fluoride ions.

\section{Results and Discussion}

\subsection{XRD and XRF Analysis}

XRD diffractograms (Figure 1 ) revealed that the major mineral in kaolin sample was kaolinite $\left[\mathrm{Al}_{2} \mathrm{Si}_{2} \mathrm{O}_{5}(\mathrm{OH})_{4}\right]$ at $\mathrm{d}=$ $7.18,4.45$, and $3.57 \AA$ around $14^{\circ}$ and $29^{\circ} 2 \theta$, respectively, subordinated with illite $\left[\mathrm{KAl}_{2}\left(\mathrm{Si}_{3} \mathrm{AlO}_{10}\right)(\mathrm{OH})_{2}\right]$ at $\mathrm{d}=3.33 \AA$ around $31^{\circ} 2 \theta$; while the minor minerals observed in kaolin were quartz $\left(\mathrm{SiO}_{2}\right)$ at $\mathrm{d}=4.16\left(24^{\circ} 2 \theta\right)$ and $3.34 \AA\left(31^{\circ} 2 \theta\right)$ and microcline $\left[\mathrm{KAlSi}_{3} \mathrm{O}_{8}\right]$ at $\mathrm{d}=4.16\left(25^{\circ} 2 \theta\right)$. In the feldspar sample (Figure 2), the prominent minerals were found to be microcline $\left[\mathrm{KAlSi}_{3} \mathrm{O} 8\right.$ ] at $\mathrm{d}=4.22\left(24^{\circ} 2 \theta\right)$ and $3.24 \AA\left(32^{\circ}\right.$ $2 \theta)$ and albite $\left[\mathrm{NaAlSi}_{3} \mathrm{O}_{8}\right]$ at $\mathrm{d}=4.02\left(26^{\circ} 2 \theta\right)$ and $3.19 \AA\left(33^{\circ}\right.$ $2 \theta)$. The minor minerals in feldspar were sanidine $\left[\mathrm{K}\left(\mathrm{Si}_{3} \mathrm{Al}\right) \mathrm{O}_{8}\right]$ identified around $27^{\circ}, 35^{\circ}$ and $54^{\circ} 2 \theta$; oligoclase $\left[(\mathrm{Na}, \mathrm{Ca}) \mathrm{Al}(\mathrm{Al}, \mathrm{Si}) \mathrm{Si}_{2} \mathrm{O}_{8}\right]$ identified by the presence of peaks 
around $38^{\circ}, 42^{\circ}, 45^{\circ}$ and $49^{\circ} 2 \theta$; and silica $\left(\mathrm{SiO}_{2}\right)$ was identified as peak at $\mathrm{d}=4.25$ and $3.34 \AA$. The same results were obtained from previous studies on the mineralogical composition of kaolin and feldspar [9].

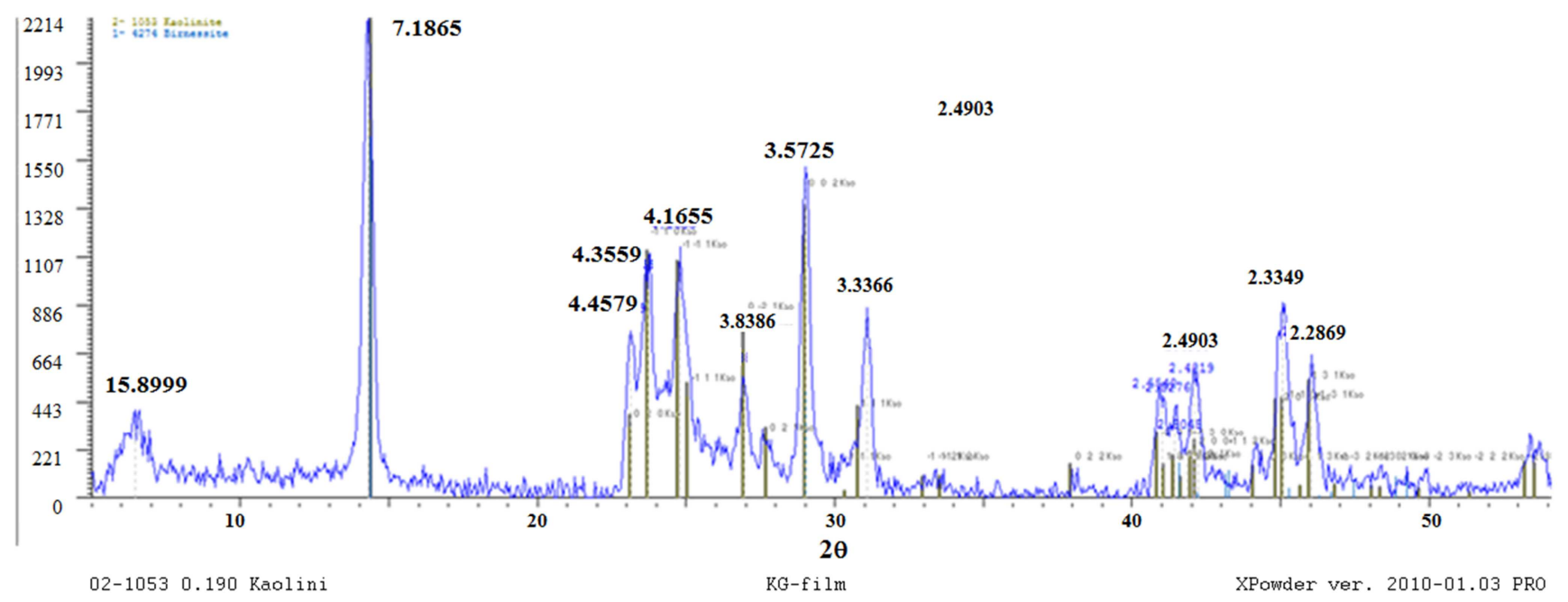

Figure 2. The Diffractogram of Kaolin.

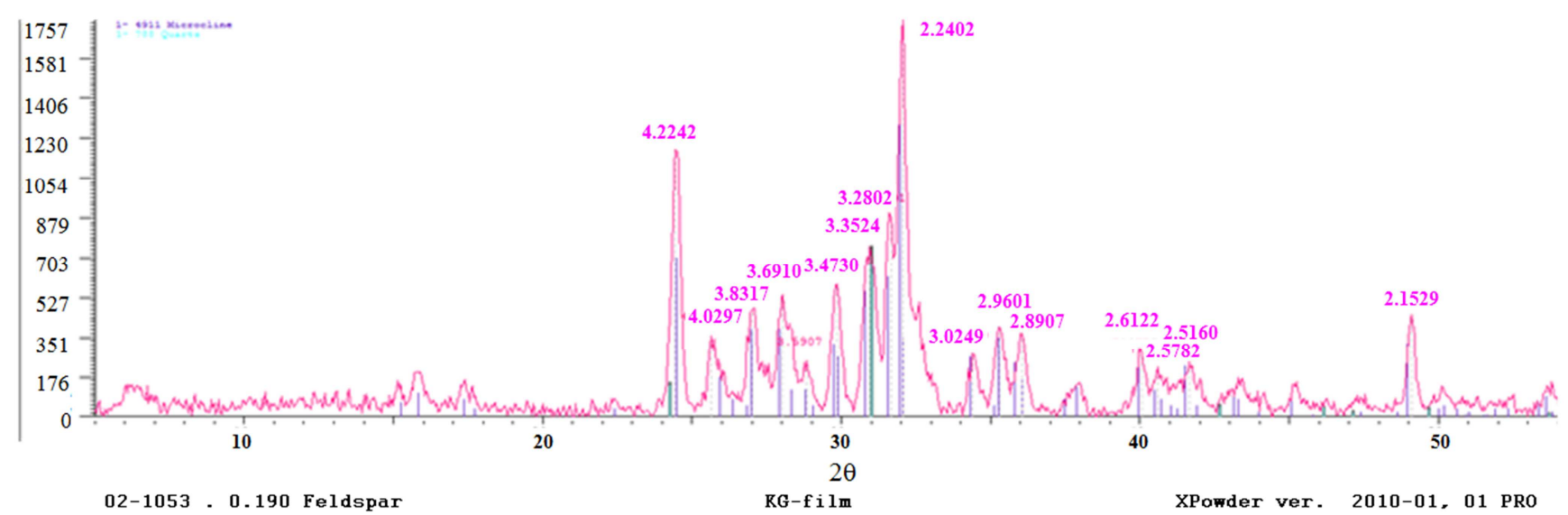

Figure 3. The Diffractogram of Feldspar.

Table 2. Chemical Composition in (\%mass) of Kaolin and Feldspar.

\begin{tabular}{lll}
\hline component & Kaolin (\%) & Feldspar (\%) \\
\hline $\mathrm{SiO}_{2}$ & 53.24 & 64.19 \\
$\mathrm{Al}_{2} \mathrm{O}_{3}$ & 35.64 & 16.95 \\
$\mathrm{~K}_{2} \mathrm{O}$ & 0.63 & 17.41 \\
$\mathrm{Na}_{2} \mathrm{O}$ & $<0.01$ & 3.29 \\
$\mathrm{Fe}_{2} \mathrm{O}_{3}$ & 2.14 & 0.23 \\
$\mathrm{TiO}_{2}$ & 0.76 & $<0.01$ \\
$\mathrm{CaO}$ & 0.06 & 0.33 \\
$\mathrm{BaO}$ & $<0.01$ & 0.24 \\
$\mathrm{SO}$ & 0.07 & 0.20 \\
$\mathrm{P}_{2} \mathrm{O}_{5}$ & 0.16 & 0.12 \\
$\mathrm{MgO}$ & 0.12 & $<0.01$ \\
$\mathrm{SrO}$ & 0.01 & 0.03 \\
$\mathrm{ZrO}$ & 0.03 & $<0.01$ \\
$\mathrm{PbO}$ & 0.03 & $<0.01$ \\
$\mathrm{Cr}$ & 0.02 & $<0.01$ \\
$\mathrm{LOI}$ & 7.07 & 0.97 \\
$\mathrm{Total}_{2}$ & 100 & 100 \\
\hline
\end{tabular}

Chemical compositions of kaolin and feldspar are presented in Table 2. Silica was predominant in both samples, with compositions of $53.24 \%$ and $64.19 \%$ for kaolinite and feldspar, respectively. Aluminium ranked the second in both samples although in kaolinite (35.64\%) it was much higher than in feldspar $(16.95 \%)$. The amount of silica in kaolin was much higher compared to the theoretical values $(46.54 \%)$ reported in the literature [10]. The amount of aluminium found in kaolin was the same as reported [9]. There was a great variation in chemical composition of $\mathrm{K}_{2} \mathrm{O}$ in the two samples. Whereas in kaolin it was $0.63 \%$, in feldspar it was $17.41 \%$. Oxides of $\mathrm{Fe}, \mathrm{Mg}, \mathrm{Na}$, $\mathrm{Ti}$ and $\mathrm{Ca}$ were present in large proportion compared to other oxides in both samples. $\mathrm{MgO}$ and $\mathrm{TiO}_{2}$ were observed to be higher in kaolin with $0.12 \%$ and $0.76 \%$, respectively, whereas in feldspar the composition was almost negligible $(<0.01 \%)$. Feldspar was found to contain $2.29 \% \mathrm{Na}_{2} \mathrm{O}$ and $0.24 \% \mathrm{BaO}$ as compared to kaolin with $<0.01 \%$.

\subsection{Water Defluoridation Studies by Kaolin-Feldspar Adsorbents}

\subsubsection{The Effect of Particle Size}

Figure 4 shows the results obtained from defluoridation experiments using $20 \mathrm{~g}$ of various particle sizes of B1, B2, B3, 
B4 and B5 for 45 minutes with initial fluoride concentration of $5.03 \mathrm{mg} / \mathrm{L}$ at $\mathrm{pH}$ of 8.2 . Four different particle sizes with average of $(2.00,1.40,0.30$ and $0.25 \mathrm{~mm})$ were studied to test the adsorption efficiency for adsorbents (B1-B5). Fluoride removal was achieved better using $\mathrm{B} 1$ and $\mathrm{B} 2$ for all particle sizes (Figure 4); the samples in which the amount of kaolin is higher than the amount of feldspar. Particle size of $0.25 \mathrm{~mm}$ showed the highest percentage removal of fluoride compared to other sizes in B1-B4. It was not possible to prepare average particle sizes of 0.25 and $0.3 \mathrm{~mm}$ for B5. Particle size of 0.25 $\mathrm{mm}$ had the highest adsorption capacity for all samples. Similar to the present work Hassen [11] reported the adsorption capacity of fluoride from fluoridated water using clay to be higher when particle size of less than $1.25 \mathrm{~mm}$ was used. Smaller particle sizes provide more surface area and sorption sites leading to greater sorption [12]. However, the particle size of $1.4 \mathrm{~mm}$ was selected for studying other parameters in this work because it was easy to park the column, pass through fluoridated water and easy to control the contact time between defluoridated water and adsorbent. In addition, this size $(1.4 \mathrm{~mm})$ showed low attrition during defluoridation.

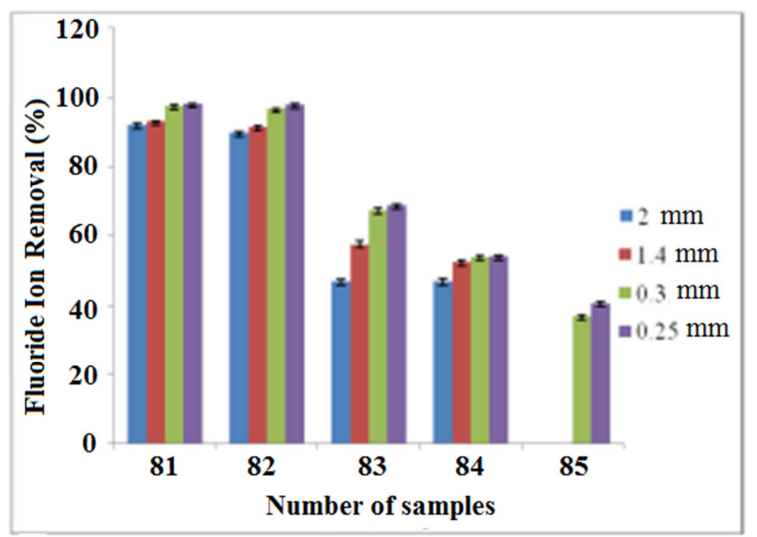

Figure 4. The Effect of Particle Size on Defluoridation (Conditions: adsorbent dose $=20 \mathrm{~g}$, initial fluoride ion concentration $=5.03 \mathrm{mg} / \mathrm{L}$, contact time $=45$ minutes, $p H=8.2$ ).

\subsubsection{The Effect of Contact Time}

Figure 5 shows the results obtained from defluoridation experiments using $20 \mathrm{~g}$ of $1.40 \mathrm{~mm}$ average particle size of activated B1, B2, B3 and B4 adsorbents at different time intervals. The initial fluoride ion concentration was $5.03 \mathrm{mg} / \mathrm{L}$ at $\mathrm{pH}$ of 8.2. From Figure5, it is seen that the amount of fluoride adsorbed increased with increase in contact time up to 30 minutes and slowly decreased upto $45^{\text {th }}$ minute where the amount of fluoride ions adsorbed remained almost constant. At the beginning the adsorbent had enough availability of vacant sites for fluoride adsorption [13], whereas later, the fluoride adsorption did not increase due to the less availability of the active sites. The decrease in the adsorption sites might be attributed to the formation of monolayer surface which blocked the outer surface for fluoride ions to be adsorbed [14]. Othman et al. [15] reported that maximum removal of fluoride using clay calcinated at $700^{\circ} \mathrm{C}$ is attained after 8 hours. However, after 12 hours the removal of fluoride remained almost constant suggesting equilibrium condition. It has been observed that B1and B2 had maximum adsorption capacity even at the beginning of the process. Generally, contact time above 45 minutes had no significant effect as the removal of fluoride almost remained constant. Therefore, defluoridation using adsorbents B1-B4 can be best achieved within 45 minutes.

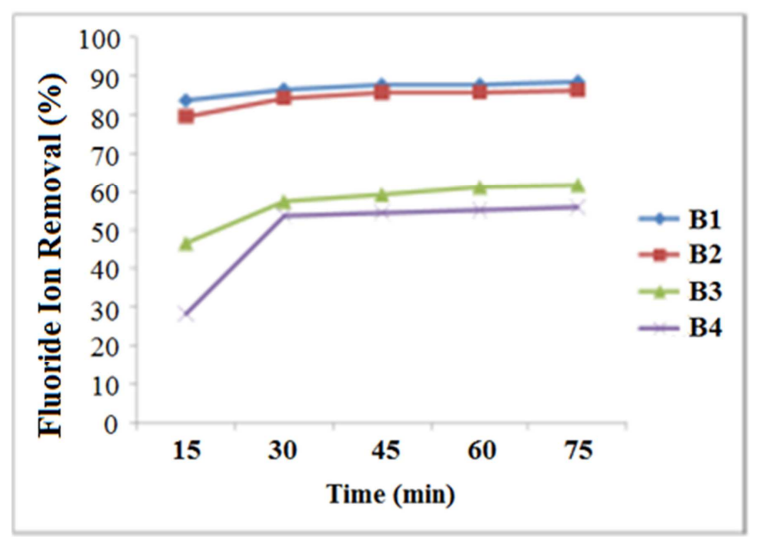

Figure 5. The Effect of Contact Time on Defluoridation(Conditions: adsorbent dose $=20 \mathrm{~g}$, particle size $=1.40 \mathrm{~mm}$, initial fluoride ion concentration $=5.03 \mathrm{mg} / \mathrm{L}, \mathrm{pH}=8.2$ ).

\subsubsection{The Effect of Initial Fluoride Concentration}

Figure 6 shows the results obtained from defluoridation experiments using $20 \mathrm{~g}$ of $1.4 \mathrm{~mm}$ particle size of activated $\mathrm{B} 1$, B2, B3 and B4 adsorbents for 45 minutes at different initial fluoride concentration at $\mathrm{pH}$ of 8.2. Results show that adsorption of fluoride from water is affected by initial fluoride concentration. Fluoride removal efficiency decreased with increasing initial fluoride concentration when other parameters (contact time, $\mathrm{pH}$, particle size and height of column) were kept constant. The highest removal of fluoride from water for B1-B4 samples was observed when the initial fluoride concentration was $5 \mathrm{mg} / \mathrm{L}$ (Figure 6); the concentration at which the adsorbents reduced fluoride to WHO acceptable limit $(<1.5 \mathrm{mg} / \mathrm{L})$. It was found that when initial fluoride concentration was varied from 5 to $25 \mathrm{mg} / \mathrm{L}$, the percentage of fluoride removal decreased from $97-79 \%$, $90-66 \%, 62-59 \%$ and $53-31 \%$ for B1, B2, B3, and B4, respectively. $\mathrm{B} 1$ had the highest removal capacity to all samples. Increase in initial fluoride concentration decreases the efficiency of fluoride removal due to saturation of active sites of the adsorbents [16].

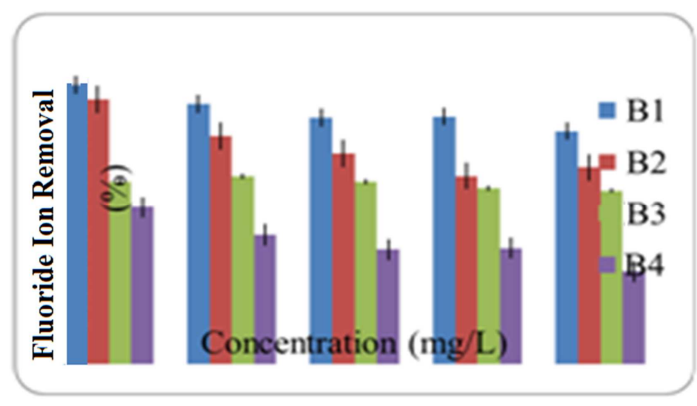

Figure 6. The Effect of Initial Fluoride Concentration on Defluoridation (Conditions: adsorbent dose $=20 \mathrm{~g}$, particle size $=1.40 \mathrm{~mm}$, contact time $=45$ minutes, $p H=8.2$ ) 


\subsubsection{The Effect of the Height of the Column}

Figure 7 shows the results obtained from defluoridation experiments using $1.40 \mathrm{~mm}$ average particle size of activated B1-B4 samples for 45 minutes with initial fluoride concentration of $5.03 \mathrm{mg} / \mathrm{L}$ at different heights of the column at $\mathrm{pH}$ of 8.2. Results show that the percentage adsorption for all adsorbent samples increased with height $(0.8,1.6,2.4,3.2$, $4.0,4.8,5.6,6.4$ and $7.2 \mathrm{~cm})$. B1 had the highest adsorption of fluoride compared to other samples. Sharp increase in adsorption for all samples was observed initially at the column height between $0.8-1.6 \mathrm{~cm}$ (Figure 7). The increase in adsorption was due to the increase of binding sites for fluoride [17]. Beyond the height of $4 \mathrm{~cm}$, the adsorption of fluoride for all samples remained almost constant. These observations are probably due to the effect of masking; the inner active sites were not able to be reached by fluoridated water [18].

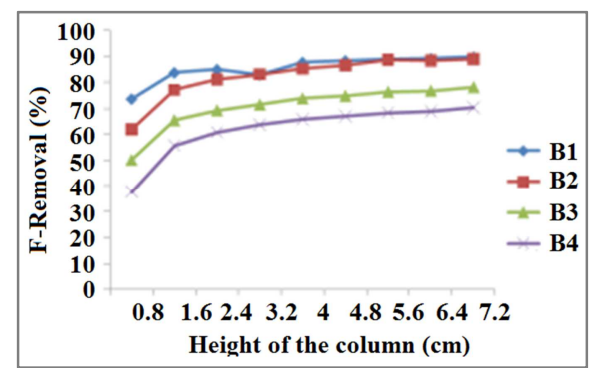

Figure 7. The Effect of Height of the Column on Defluoridation (Conditions: particle size $=1.40 \mathrm{~mm}$, initial fluoride ion concentration $=5.03 \mathrm{mg} / \mathrm{L}$, contact time $=45$ minutes, $p H=8.2$ ).

Generally, the observation made in this study was that, defluoridation is proportional to height of the column. However, the minimum height giving maximum fluoride adsorption was $4 \mathrm{~cm}$.

\subsubsection{The Effect of $\mathrm{pH}$}

Figure 8 shows the results obtained from defluoridation experiments using $20 \mathrm{~g}$ of activated B1-B4 samples $(1.40 \mathrm{~mm}$ average particle size); contact time of 45 minutes; initial fluoride concentration $5.03 \mathrm{mg} / \mathrm{L}$; and $\mathrm{pH}$ varied from 2 to 14 . Results show a $\mathrm{pH}$ dependent of fluoride ions adsorption. Fluoride adsorption decreased with increase in the $\mathrm{pH}$ of the solution. Maximum fluoride adsorption of over $98 \%$ was afforded by all adsorbents (B1-B4) with $\mathrm{pH} 2$ of the fluoridated water. With $\mathrm{pH} 14$, the maximum fluoride removal achieved was about $60 \%$ only from B1.

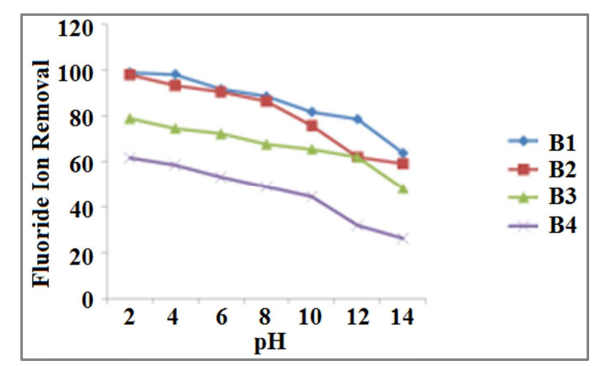

Figure 8. The Effect of pH on Defluoridation(Conditions: adsorbent dose $=20$ $\mathrm{g}$, particle size $=1.40 \mathrm{~mm}$, initial fluoride ion concentration $=5.03 \mathrm{mg} / \mathrm{L}$, contact time $=45$ minutes).

\subsubsection{The Regeneration of the Fluoride Saturated Adsorbent}

Figure 9 shows the results obtained when the saturated B1 was regenerated. It is clearly observed that, regeneration had almost negligible effect on recovering the capacity of B1 to adsorb fluoride from contaminated water. The first cycle reduced fluoride ions from 5.03 to $2.4 \mathrm{mg} / \mathrm{L}$. However, even the first cycle did not reduce the amount of fluoride to acceptable limit which is $1.5 \mathrm{mg} / \mathrm{L}$ as reported by [3]. Therefore regeneration of $\mathrm{B} 1$ has no additional value on fluoride ion removal in water contaminated with fluoride.

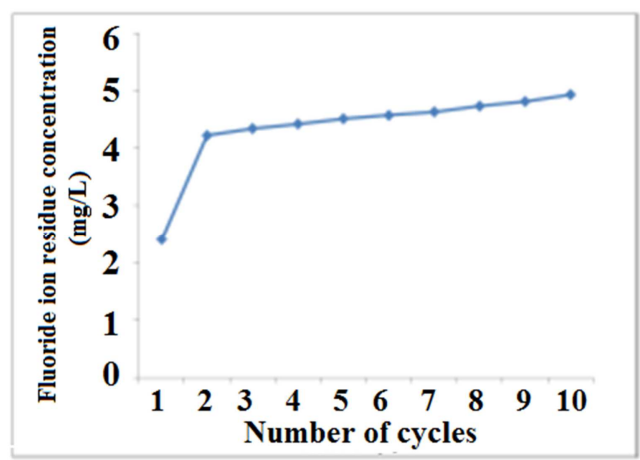

Figure 9. The Effect of Regeneration B1.

\section{Conclusion}

The major chemical compositions of kaolin are $\mathrm{SiO}_{2}$ and $\mathrm{Al}_{2} \mathrm{O}_{3}$, whereas feldspar consists of $\mathrm{SiO}_{2}, \mathrm{Al}_{2} \mathrm{O}_{3}$ and $\mathrm{K}_{2} \mathrm{O}$. The main mineralogical components of kaolin are kaolinite $\left[\mathrm{Al}_{2} \mathrm{Si}_{2} \mathrm{O}_{5}(\mathrm{OH})_{4}\right]$, illite $\left[\mathrm{KAl}_{2}\left(\mathrm{Si}_{3} \mathrm{AlO}_{10}\right)(\mathrm{OH})_{2}\right]$ and quartz $\left(\mathrm{SiO}_{2}\right)$ while feldspar consists of microcline $\left(\mathrm{KAlSi}_{3} \mathrm{O}_{8}\right)$ and quartz $\left(\mathrm{SiO}_{2}\right)$. Results show that for all samples, the smallest particles of $0.25 \mathrm{~mm}$ size had higher fluoride adsorption capacities. Time of contact for all samples had an effect on defluoridation. Initially the rate of removal of fluoride increased very fast up to $30^{\text {th }}$ minute then slowly to $45^{\text {th }}$ minute and remained almost constant beyond that time. Fluoride removal efficiency decreased with increasing initial fluoride concentration. The highest removal of fluoride from water for B1-B4 adsorbents was observed when the initial fluoride was $5 \mathrm{mg} / \mathrm{L}$. Small $\mathrm{pH}$ ranges $(\mathrm{pH} 2-6)$ reduced much fluoride from contaminated water with the highest fluoride removal at $\mathrm{pH} 2$ as a result of increase of positively charged ions. Also defluoridation increased with an increase in the height of the column.

However, from the current results, blending kaolin and feldspar did not improve adsorption of fluoride ions from fluoridated water. The best adsorbent was B1 which consists of kaolin only followed by B2 with 2:1 kaolin-feldspar ratio.

\section{References}

[1] WHO, Fluoride in drinking-water. Background document for development of WHO guidelines for drinking water quality. Geneva 2004, p. 1-7. 
[2] Tiemann, M., Flouride in drinking water: A review of fluoridation and regulations issues: Report for congress congressional research services. 2013, p. 1-21.

[3] Gumbo, F. J. and Mkongo, G., Defluoridation for rural fluoride affected communities in Tanzania. Proceedings of the 1st International workshop on fluorosis and defluoridation of water Ngurdoto, Tanzania. 1995, p. 109-114.

[4] Ayoob, S. and Gupta, A., Fluoride in drinking water: A review on the status and stress effects: Crit. Rev. Environ. Sci. Technol. 36, 2006, p. 433-487.

[5] Bjorvatn, $\mathrm{K}$ and Bårdsen, A., Use of activated clay for defluoridation of water. Proceedings of the 1stInternational workshop on fluorosis and defluoridation of water, Ngurdoto, Tanzania. 1995, p. 49-55.

[6] Fawell, J. K., Bailey, K., Chilton, J., Dahi, E., Fewtrell, L. and Magara, Y., Fluoride in drinking water, World Health Organisation. IWA Publishing, London. 2006, p. 1-134.

[7] Feenstra, L., Vasak, J. and Griffioen, J., Fluoride in groundwater overview and evaluation of removal methods, Report SP 2007-1. International groundwater resources assessment centre, Utrecht. Netherland. 2007, p. 1-21.

[8] Thole, B., Ground water contamination with flouride and potential flouride removal technologies for East and Southern Africa; Perspective in water pollution, Dar, A. I. (Ed.), 2013, p. 65-91.

[9] Lugwisha, E. H. J., Thermal and X-ray investigation of Kowak clay in Northern Tanzania and its possible industrial use. Tanz. J. Sci. 32(2), 2006, p. 81-90.

[10] Al-ani, T. and Sarapaa, O., Clay and clay mineralogy: physical-chemical properties and industrial uses. Geologian Tutkuskeskus. 19, 2008, p. 6-15.
[11] Hassen, A., Selection of clay adsorbents and determination of the optimum condition for defluoridation of ground water in Rift Valley Region. MSc Thesis. 2007, Addis Ababa University.

[12] Harikumar, P. S P., Jaseela, C. and Megha, T., Defluoridation of water using biosorbents. Nat. Sci. 4(4), 2012, p. 245-251.

[13] Vijaya, Y. and Krishnaiah, A., Sorptive response profile of chitosan coated silica in the defluoridation of aqueous solutions. J. Chem. 6(3), 2009, p.713-723.

[14] Waheed, S., Attar, S. and Waghmare, M., Investigation on sorption of fluoride in water using rice husk as an adsorbent. Int. Q. J. 8, 2009, p. 217-223.

[15] Othman, O. C., Philip, J. Y. N. and Nkinda, M. S., Use of activated red clay soil from Kiteto district, Tanzania, as a remedial method for high fluoride levels in drinking water. Int. J. Sci. Technol. Soc. 2(5), 2014, p. 115-120.

[16] Fentanun, A., Adsorptive removal of fluoride from water using nano scale aluminium oxide hydroxide. MSc Thesis. 2010, Addis Ababa University.

[17] Anil, K. S. and Manoj, K. S., An innovative technique for removal of fluoride from drinking water. Ambernath India 2, 2012, p. 133-140.

[18] Kefyalew, G., Zewge, F., Hundhammer, B. and Megersa, N., Fluoride removal by adsorption on thermally treated lateritic soils pritend in Ethiopia. Chem. Soc. Ethiop. 26, 2012, p. 361-372. 